удручающее впечатление. «Ни разу больше, - вспоминал Иванов, - ни в каком учреждении “Земского края" не бывала моя нога» [5, с. 395]. Из Владивостока Вс. Н. Иванов отплыл в эмиграцию 22 октября 1922 г., за три дня до вступления в город «красных» войск ДВР и партизан.

Эпопея кипучей деятельности Вс. Н. Иванова в стане «меркуловцев» вместила в себя многое: энтузиазм первых месяцев, разочарование в друзьях и идеалах, выстраивание работы редакций и издательских организаций, радость творчества и горечь расставания с Родиной. Не поместилось в ней только примирение с большевистской Россией - слишком свежи были раны прошедших лет. Осознание своей сопричастности судьбе страны, перекроенной революцией, пришло к писателю спустя десятилетие, в начале 1930-х гг.

\section{СПИСОК ЛИТЕРАТУРЫ}

1. Якимова С.И. Всеволод Никанорович Иванов: писатель, мыслитель, журналист. Хабаровск : Изд-во ТОГУ, 2013. 215 с.

2. Всеволод Никанорович Иванов - писатель и философ: к 125 -летию со дня рождения писателя : биобиблиогр. указ. / сост. Т.В. Кирпиченко. Хабаровск, 2013. 84 с.

3. «Непрерывное движение духа...»: Дневник и записные книжки Вс. Н. Иванова. Хабаровск, 2012. 380 с.
4. Ситников М.Г. Редактор газеты «Сибирские стрелки» // Белая армия. Белое дело: ист. науч.-популяр. альманах. Екатеринбург, 2011. № 19. С. 55-97.

5. Иванов Bc. Н. Исход: воспоминания / В.Н. Иванов; под общ. ред. М.Ф. Асламова. Хабаровск: Союз писателей России, Хабар. регион. отд-ние, 2008. 400 с.

6. Владивосток, 1922 год: жизнь города на страницах газеты «Голос Родины» / сост. и ред. Н.А. Троицкая. Владивосток : Рос. гос. ист. архив Дальнего Востока, 2012. 138 с.

\section{REFERENCES}

1. Yakimova S.I. Vsevolod Nikanorovich Ivanov: a writer, thinker, journalist. Khabarovsk, 2013, 215 p. (In Russ.)

2. Vsevolod Nikanorovich Ivanov - a writer and philosopher: on the 125th anniversary of the writer: biobibliographic index / comp. T.V. Kirpichenko. Khabarovsk, 2013, 84 p. (In Russ.)

3. "Spirit continuous movement ...": a diary and notebooks by Vs. N. Ivanov. Khabarovsk, 2012, 380 p. (In Russ.)

4. Sitnikov M.G. Editor of newspaper "Sibirskiye Strelki". Belaya armiya. Beloye delo: Ist. nauch.-popular. alm. Ekaterinburg, 2011, no 19, pp. 55-97 (In Russ.)

5. Ivanov VS. N. Exodus: Memoirs. Khabarovsk, 2008, 208 p. (In Russ.)

6. Vladivostok 1922: city life on pages of newspaper "Golos Rodiny" / comp. a. ed. N.A. Troitskaya. Vladivostok, 2012, 138 p. (In Russ.)

Статья принята редакиией 20.07.2015

DOI: $10.15372 / \mathrm{HSS} 20150310$

УДК 002.5(09)

\title{
Н.С. ЛИСОВСКАЯ
}

\section{НАУЧНЫЕ ИЗДАНИЯ СИБИРСКИХ ФИЛИАЛОВ АКАДЕМИИ НАУК (1946-1950-е гг.)}

\author{
Наталья Сергеевна Лисовская, \\ заведующая сектором, \\ Государственная публичная научно-техническая библиотека СО РАН, \\ РФ, 630200, г. Новосибирск, ул. Восход, 15 \\ e-mail: linaseveda@mail.ru
}

В статье поставлена цель - воссоздать историю зарождения научной периодики сибирских филиалов Академии наук СССР в 1946 1950-е гг. В качестве источниковой базы привлекались библиографические указатели, архивные документы, материалы академической периодической печати, а также сами издания «de visu». В результате было установлено, что выпуск научных изданий сибирскими академическими коллективами на момент организации Сибирского отделения явился важным подготовительным этапом в процессе дальнейшего развития системы научной периодики. Инициатива и активная поддержка Академии наук СССР объединила усилия филиалов в создании первого регионального журнала - «Известия восточных филиалов АН СССР» и во многом способствовала дальнейшему развитию издательской деятельности.

Ключевые слова: научные издания, научные журналь, “Известия Восточных филиалов Академии наук», издательская деятельность, Академия наук СССР, Западно-Сибирский филиал, Якутский филиал, Восточно-Сибирский филиал. 
N.S. LISOVSKAYA

\title{
THE SCIENTIFIC PUBLICATIONS OF THE SIBERIAN BRANCHES OF THE ACADEMY OF SCIENCES (1946-1950s)
}

\author{
Natalya S. Lisovskaya, \\ Head of Sector, \\ State Public Scientific Technical Library SB RAS, \\ 15, Voshod str., Novosibirsk, 630200, Russian, \\ e-mail: linaseveda@mail.ru
}

\begin{abstract}
The purpose of the work is to reconstruct the origins of scientific periodicals of the Siberian Branches of the Academy of Sciences. The chronological outline of the process of organization and development of the Siberian Branches of Academy is necessary for the purpose identified. A variety of sources helped to compile a list of periodicals, issued by organizations of the Branches in 1946-1950s; to study them «de visu» and to describe their specific features. The available archival documents, for the first time introduced into scientific use, and academic periodicals were helpful in understanding the role of Academy of Sciences in the development of publishing activities of Siberian Institutes. Analysis of the data obtained has shown, that publishing of scholarly periodicals by the academic teams at the moment of setting up the Siberian Branches of Academy of Sciences was an important preparatory stage in the development of the system of SB RAS scholarly periodicals.

The initiative and active support of the USSR Academy of Sciences helped to join efforts of Academic Branches for establishment of their first regional journal - «Izvestiya Vostochnykh filialov AN SSSR» but in many ways contributed to further development of their publishing activities. Difficulties encountered in publication of scientific literature in the cities of Siberia confirmed the necessity of creating their own print production, training their own personnel and improving the publishing culture.
\end{abstract}

Keywords:periodicals, journal, «Izvestiya Vostochnykh filialov AN SSSR», publishing activities, Academy of Sciences of the USSR, West-Siberian Branch, East-Siberian Branch, Yakut Branch.

Журналы, выпускаемые научными коллективами Сибирского отделения Российской Академии наук (CO РАН), являются составной частью системы академических журналов и занимают в ней достойное место. Однако в поле зрения историко-книговедческих исследований до сих пор не попадали вопросы зарождения, развития и этапы становления этой системы. Имеющиеся в небольшом количестве публикации содержат лишь отрывочные сведения, констатирующие скупые цифры по итогам издательской работы в контексте создания полиграфической базы для научного книгоиздания Сибири $[1 ; 2 ; 3]$.

Вместе с тем изучение и анализ обстоятельств формирования системы сибирской научной периодики представляют интерес не только для выявления ее специфических черт и особенностей научного книгоиздания в Сибири, но и для создания полной картины истории академического книгоиздания, для понимания роли Академии наук СССР в этих процессах.

Постановление Совета Народных Комиссаров СССР от 21 октября 1943 г. о создании Западно-Сибирского филиала Академии наук СССР (ЗСФ АН СССР) положило начало организации стационарной академической структуры в регионе. Послевоенное восстановление и дальнейшее развитие народного хозяйства указали на необходимость активного освоения ресурсов Сибири и «...радикального изменения в структуре научного потенциала региона, что привело не просто к количественному росту научных учреждений, а к изменению качества научного потенциала, его квалификационного уровня и принципиально иным ориентациям новых научных струк- тур» [4, с. 83]. Новосибирск, благодаря своему экономико-географическому положению, стремительному росту промышленного потенциала и мощи эвакуированных во время войны предприятий, стал городом, способным наилучшим образом обеспечить условия для развития науки $[5$, с. $72-74 ; 6 ; 7]$. В феврале 1944 г. Президиум АН СССР назначил руководящий состав ЗСФ. Были намечены территориальные границы филиала, охватившие Новосибирскую, Омскую, Томскую и Тюменскую области, а также Алтайский и Красноярский края, где должны были развиваться следующие направления научно-исследовательской деятельности:

- изучение ископаемых богатств Западной Сибири с целью подготовки и расширения сырьевой базы черной и цветной металлургии;

- создание эффективных способов добычи полезных ископаемых и

разработка новых технологических процессов извлечения металлов;

- разработка научных основ некоторых отраслей химической промышленности (углехимического синтеза);

- изыскание путей и способов наиболее целесообразного использования громадных энергетических ресурсов и развития транспортных связей;

изучение растительных богатств Западной Сибири и ее животного мира $[5 ; 6]$.

Соответственно научным направлениям были созданы Горно-геологический, Химико-металлургический, Транспортно-энергетический и Медико-биологический институты. 
О завершении организационного периода в создании ЗСФ АН СССР и предварительных итогах научной деятельности академик А.А. Скочинский доложил в январе 1945 г. [6; 8]. Президиум АН СССР одобрил деятельность филиала и признал, что «за короткий срок руководство добилось укомплектования институтов кадрами местных ученых ${ }^{1}$ и создало необходимые материальные условия для плодотворной научной работы». Для дальнейшей работы филиала был намечен ряд конкретных мер, среди которых Редакционно-издательскому совету АН СССР поручалось: «...выяснить возможность включения в план 1946 г. издания трудов Филиала» [9]. Таким образом, были подчеркнуты важность и понимание необходимости организации собственных научных изданий как средства информирования научной общественности страны о результатах исследовательской деятельности сибирских ученых и предприняты первые практические шаги для воплощения этих мер в жизнь.

Дальнейшее развитие и расширение академической науки в Сибири было связано с проблемами освоения потенциала гидроэнергетических, топливных и сырьевых ресурсов Восточной Сибири. Решение этих задач стало важнейшим основанием при обсуждении вопроса об организации филиалов Академии в Восточной Сибири и Якутии. В 1947 г. в Якутии была создана академическая база, которая в 1949 г. переименована в Якутский филиал (ЯФ) АН СССР. В период 1947-1957 гг. в республике созданы НИИ языка и литературы с несколькими секторами; химическая лаборатория; станция по изучению космических лучей; Институт биологии, Институт геологии [6]. В феврале 1949 г. по распоряжению Совета Министров СССР в Иркутске организуется Восточно-Сибирский филиала АН СССР (ВСФ АН СССР), в структуру которого вошли Институт геологии, Институт энергетики и химии, биологический сектор, географо-экономический сектор. Позднее были организованы Читинская и Бурят-Монгольская исследовательские группы. В сферу научно-исследовательской деятельности филиала включались Бурятская АССР, Иркутская и Читинская области $[6 ; 10]$.

Осуществляемая стратегия развития академической науки на востоке страны позволила к 1956 г. организовать за Уралом работу шести филиалов (Уральского, Западно-Сибирского, Восточно-Сибирского, Якутского, Дальневосточного и Сахалинского), а также предусмотреть их специализацию, преодоление дублирования в научных исследованиях и обеспечение концентрации научных работ на направлениях, наиболее важных для развития производительных сил соответствующих территорий. Признавая приоритеты прикладного характера проводимых научных изысканий и их ориентацию на обслуживание

${ }^{1}$ На 01.01.1945 г. в учреждениях филиала работали 130 coтрудников, из них 73 научных работника, в том числе 1 академик, 1 заслуженный деятель науки, 25 докторов и 36 доцентов и кандидатов наук [9]. региональных потребностей, одновременно предполагалось повышение уровня фундаментальности осуществляемых в филиалах работ, укрепление теоретических изысканий и формирование научных советов по важнейшим исследовательским проблемам $[5$, c. 83]. Перед сибирскими учеными были выдвинуты четко обозначенные задачи, решение которых достаточно скоро стало приносить и первые результаты. Накапливаемая «научная продукция» требовала оперативного опубликования, в связи с чем стали организовываться собственные сибирские издания. Всего выявлено 10 наименований изданий, выходивших в 1946 - 1950-е гг., среди них «Известия...», «Труды» и «Научные сообщения» ${ }^{2}$.

Одним из первых следует отметить «Известия Западно-Сибирского филиала АН СССР», выходившие в двух сериях с 1946 г. Отмечая внешнее сходство с центральными академическими журналами, остановимся на особенностях этого издания. На титульном листе «Известий Западно-Сибирского филиала АН СССР. Сер.: Биологическая» (1946-1951)3 слово «Известия» вынесено в область заглавия, ниже приведено название серии. В первых номерах имелось уточнение на французском языке - «Bulletin de la Filiale de Siberie Occidentale de l'Academie des Sciences de L'URSS». Далее указаны редактор и место издания (на русском и французском языках). Содержание номеров тематически не структурировано, однако с 1948 г. материалы подбирались в рамках «ботанической» и «зоологической» подсерий с пометкой на обложке и титульном листе. Номера небольшого объема (4-5 п.л., 64-80 с.) содержали от 3 до 7 статей. Чертежи, графики, фотоснимки и рисунки почти не использовались. Статьи оформлялись без соблюдения единых предложенных правил. Даты поступления материала в редакцию и адрес автора (название организации) не приводились. Тематика статей посвящена результатам изучения сибирского края. Выпуски 1946-1948 гг. имели тираж 1000 экз., который в 1949 г. сократился до 300 экз. Всего вышло 7 выпусков, в которых было опубликовано 36 статей 20 авторов.

«Известия Западно-Сибирского филиала АН СССР. Сер.: Геологическая» (1946-1950) 4 заявлены как сборник, ответственным за выпуск которого являлся научный коллектив Горно-геологического института ЗСФ АН СССР. Содержание номера тематически структурировано: «Горное дело», «Геология», «Краткие сообщения», «Информация». Номер достаточно большого объема (10,5 п.л., 167 с.) включал 12 статей 12 авторов; иллюстративный материал использовался довольно широко. «Известия....»

${ }^{2}$ Сводный каталог периодических и продолжающихся изданий Сибири и Дальнего Востока 1789-1980 гг. Новосибирск, 1989. 640 с. [п. 688, 689, 737, 1982, 2172, 2208, 2043, 2035, 1169, 2222, 2223, 2224 2225, 2226, 1974, 1169].

3 Там же, п. 688.

4 Там же, п. 689. 
печатались в Типографии № 1 г. Новосибирска тиражом 1000 экз., причем указывался специалист, ответственный за выпуск. В результате изучения библиографических указателей ${ }^{5}$ каталогов, а также консультаций, полученных в библиотеках НИУ СО РАН, удалось выяснить, что из печати вышел только один номер (1946 г.) геологической серии вместо указанных четырех.

«Труды» и «Научные сообщения», за выпуск которых отвечали как отдельные институты, так и филиалы в целом, содержали статьи, доклады и представлялись как сборники («Труды Химико-металлургического института», «Труды ЯФ») или как непериодические серии («Научные сообщения ЯФ АН СССР»), и даже как книги («Труды ВСФ, сер.: Техническая. - Иркутск, 1956. Вып. 9: Полукоксование углей Восточной Сибири).

Первые выпуски изданий филиалов объединяли материалы в широких тематических границах, однако постепенно происходило сужение специализации изданий, в результате появлялись такие серии и подзаголовки, как «Энергетическая», «Транспортная», «Химическая», «Вопросы докембрия Западной Сибири», «О химизме спекания сульфат-глиноземных шихт» и др.

Объемы изданий были различными: от 6-7 п.л. (100 стр., 5-7 статей в номере) имели «Труды» Транспортно-энергетического, Химико-металлургического институтов и «Труды Восточно-Сибирского филиала. Сер.: Геологическая» до 10 п.л. (200 стр., 8-10 статей) доходили объемы таких изданий, как «Труды ГорноГеологического института».

Тиражи колебались от 320-500 до 1700 экз. В изданиях указывались ответственные редакторы («Труды» Транспортно-энергетического, Горно-Геологического институтов) или редакционная коллегия («Труды Восточно-Сибирского филиала»). Материалы активно иллюстрировались рисунками, схемами, фото, однако по-прежнему оформлялись без соблюдения единых правил. Труды печатались как на местах - в Новосибирске, Иркутске, Якутске, так и в типографиях Академии наук СССР в Москве или Ленинграде. Круг лиц, ответственных за выпуск, расширялся за счет редактора издательства, художественного и технического редакторов, корректоров.

Малочисленность специалистов по отдельным проблемам в сибирских филиалах приводила к тому, что один научный сотрудник являлся автором и соавтором большей части помещенных в номере статей, например: «Труды Химико-металлургического института», 1957. Вып. 10: научный сотрудник Е.Н. Лоскутова выступает как автор и соавтор 7 из 15 статей; «Труды ВСФ. Сер.: Химическая», 1955. Вып. 3: Исследование Черемховских углей и продуктов их химической пере-

5 Периодическая печать СССР 1917-1949. Журналы, Труды и Бюллетени по естественным наукам и математике: библиогр. указатель. М.: Изд-во Всесоюзной книжной палаты, 1956 C. 73,109 . работки. В. Калечиц является автором и соавтором 11 из 17 статей.

Постепенно издания филиалов АН СССР приобретали облик классических «Трудов» ${ }^{6}$. И хотя немногочисленные научные коллективы еще не могли самостоятельно поддерживать строгую периодичность публикаций, организация собственных сборников, во-первых, продемонстрировала растущий научный потенциал, а во-вторых, опубликованные материалы являлись результатами решения широкомасштабных задач по освоению ресурсов региона и представляли большой интерес для ученых страны.

В связи с этим встал вопрос о создании регулярного научного издания - журнала, общего для всех сибирских филиалов. Решение этого вопроса было оформлено в «Распоряжении Президиума АН СССР № 55-2468 от 12 ноября 1956 г.» об организации постоянно действующего в сибирском регионе научного периодического издания. Распоряжение подписано Президентом АН СССР А.А. Несмеяновым и Главным ученым секретарем Президиума АН А.В. Топчиевым ${ }^{7}$ Документ предписывал Совету по координации научной деятельности АН союзных республик и филиалов организовать при ЗСФ издание журнала «Известия восточных филиалов АН СССР» периодичностью 12 номеров в год, объемом одного номера 10 п.л. и тиражом 3000 экз.

Издавать журнал было предложено Новосибирскому областному издательству с возмещением расходов из фондов АН СССР. Перед журналом ставились задачи: «освещение результатов новых научных исследований; обмен опытом научно-организационных мероприятий по вопросам координации научных работ по физико-математическим, химическим, геологическим, биологическим, техническим, экономическим и гуманитарным наукам». Были утверждены главный редактор и состав редакционной коллегии. Редакцию журнала рекомендовано организовать при Президиуме $3 С \Phi^{8}$.

В свою очередь, Совет по координации научной деятельности АН союзных республик и филиалов подготовил документ № 55-670 от 12 ноября 1956 г. на имя председателя Президиума ЗСФ Т.Ф. Горбачева, в котором сообщалось об организации Президиумом АН СССР с 1 января 1957 г. журнала «Известия восточных филиалов АН СССР». Совет призвал научные коллективы к активному сотрудничеству в новом журнале, а редакционной коллегии рекомендовал приступить к выполнению своих обязанностей не позднее декабря 1956 г. В документе определены требования к содержанию подаваемого материала

6 Труды - это «произведение печати, выходящие по мере накопления материала, без строгой периодичности, под общим названием, нумерованными выпусками, не повторяющимися по содержанию, однотипно оформленные, непостоянного объема» [11, c. 428].

${ }^{7}$ Научный архив Сибирского отделения РАН (далее - НАСО). Ф. 1. Оп. 1. Д. 997б. Л. 387-388.

8 Там же. 
Количество статей, опубликованных в журнале «Известия восточных филиалов АН СССР» в 1957 г., по тематическим разделам

\begin{tabular}{|c|c|c|c|c|c|c|}
\hline \multirow{2}{*}{$\begin{array}{l}\text { Наименование организаций, } \\
\text { публиковавшихся в журнале }\end{array}$} & \multicolumn{6}{|c|}{ Тематические разделы журнала и количество опубликованных в них статей } \\
\hline & экономика & геология & химия & $\begin{array}{c}\text { технические } \\
\text { науки }\end{array}$ & биология & хроника \\
\hline Башкирский филиал АН СССР & - & 2 & - & - & 2 & - \\
\hline Восточносибирский филиал АН СССР & 1 & 6 & 7 & - & 10 & - \\
\hline Дальневосточный филиал АН СССР & - & 3 & 1 & 2 & 1 & - \\
\hline Западносибирский филиал АН СССР & 3 & 17 & 2 & 27 & 16 & - \\
\hline Уральский филиал АН СССР & 1 & 3 & 13 & 4 & - & - \\
\hline Якутский филиал АН СССР & - & 4 & - & - & 3 & - \\
\hline Другие организации* & 1 & 5 & 8 & 7 & 4 & - \\
\hline Всего статей по тематическим разделам & 6 & 40 & 31 & 40 & 36 & $19 * *$ \\
\hline
\end{tabular}

* Другие организации включают: Институт общей и теоретической химии АН СССР им. Н.С. Курнакова, Байкальская лимнологическая станция при Восточносибирском филиале АН СССР, Институт горючих материалов АН СССР, Сахалинский комплексный научно-исследовательский институт, Новосибирский институт инженеров железнодорожного транспорта, Совет по изучению производительных сил АН СССР

** Статьи раздела «Хроника» подготовлены редакцией журнала.

и необходимое условие «иметь положительное заключение Ученого совета института или научного совещания отдела, лаборатории, подчиненных непосредственно Президиуму ЗСФ, а по научно-организационным вопросам - Президиума филиала». В заключение сказано: «Издание журнала - общее дело всех научных коллективов филиала», необходимо «оправдать доверие ЦК КПСС, разрешившего филиалу АН иметь свой первый научный журнал» ${ }^{9}$.

Изучение номеров «Известий восточных филиалов АН СССР», а также данные библиографических указателей ${ }^{10}$ и каталогов библиотек НИУ СО РАН позволили установить, что всего вышло 12 номеров (1957 г.) этого издания.

Журнал «Известия восточных филиалов...» соответствовал образцу журналов АН СССР. На обложке журнала в область ответственности вынесено - «Академия наук СССР», в область заглавия - «Известия восточных филиалов Академии наук СССР», выходные данные показывают порядковый номер $(1,2, \ldots)$, год «1957» и место издания - «Новосибирское книжное издательство». Помещенное на обороте обложки оглавление имеет разделы: «Экономика», «Геология», «Химия», «Технические науки», «Биология», «Хроника», а также «Критика и библиография».

На титульном листе в области ответственности уточняется: «Совет по координации научной деятельности АН союзных республик и филиалов АН СССР». На обратной стороне титульного листа указаны адрес редакции ${ }^{11}$ и состав редакционной коллегии: Ю.П. Булашевич, д-р физ.-мат. наук (УрФ); А.И. Горбанев, д-р тех. наук, глав. ред. (Совет по координации АН СССР); Т.Ф. Горбачев, проф., зам. глав.

\footnotetext{
9 Там же. Л. 385-386.

${ }^{10}$ Сводный каталог периодических и продолжающихся изданий..

${ }^{11}$ г. Новосибирск, ул. Мичурина, 23
}

ред. (ЗСФ); К.Н. Коржавин, д-р техн. наук (ЗСФ); В.А. Кротов, канд. экон. наук (ВСФ); М.М. Одинцов, д-р геол.-мин. наук (ВСФ); Г.Л. Поспелов, канд. геол.-мин. наук (ЗСФ); В.П. Ревебцов, канд. тех. наук (УрФ); С.А. Соболевская, д-р биол. наук (ЗСФ). Важно отметить, что в редколлегию, помимо сибирских ученых, входили представители Уральского филиала АН СССР, что способствовало сотрудничеству и координации исследований между филиалами Академии наук СССР.

В редакционной статье, открывавшей 1-й номер, подчеркивалось, что настоящее издание - журнал; формулировались причины его появления и программа развития журнала $[12$, с. 3$]$; в рубрике «От редакции» были приведены правила оформления подаваемого для публикации материала. Номера были достаточно большого объема - в среднем 12 п.л. (13-18 статей); материал оформлен в соответствии с предложенными требованиями; в конце каждой статьи указывалась «географическая принадлежность» автора (название организации, филиал); а с № 4/5 - дата поступления статьи в редакцию. Статьи снабжены иллюстративными материалами. «Известия....» печатались Новосибирским книжным издательством на базе Типографии № 1 Полиграфиздата. Издание имело технического редактора и корректора. Тираж составлял 1000-1100 экз. (№ 1 вышел тиражом 2000 экз.).

В таблице показано, что количество опубликованных по тематическим рубрикам статей, примерно равное (от 30 до 40). Анализ «географической принадлежности» авторов позволил выявить приоритетные направления работы филиалов, например: ЗСФ - работы по геологии, биологии и техническим наукам, а Уральский филиал - исследования в области химии. Изучение сроков поступления материалов в редакцию показало, что в среднем рукописи рассматривались 1-3 мес., в редких случаях - 4-5 мес. Достаточно малые сроки подготовки статей можно объ- 
яснить тем, что в «молодом» региональном издании редакционный портфель заполнялся не так активно, как в центральных более известных и авторитетных, к тому же материалы предварительно рассматривались и получали одобрение на ученых советах самих НИУ.

Таким образом, издание трудов и учреждение общего журнала сибирскими филиалами АН (1946 1950-е гг.) явилось важным подготовительным этапом, который заложил основы для дальнейшего развития системы научных журналов СО РАН. Ведущая роль Академии наук проявилась в инициативе и активной поддержке усилий ученых Сибири по организации издательской деятельности. Первый сибирский научный журнал - «Известия восточных филиалов АН СССР» стал официальным органом академических структур за Уралом, и научное сообщество страны получило возможность регулярно знакомиться с результатами исследований ученых Сибири. Издательская практика помогла выявить сильные и слабые стороны, а также указала на необходимость строительства собственной полиграфической базы, подготовки высококвалифицированных кадров и повышения издательской культуры.

\section{СПИСОК ЛИТЕРАТУРЫ}

1. Лютов С.Н. Организация академического издательства в Сибири. Документальные страницы истории (1957-1958 гг.) // Библиосфера. 2011. № 4. С. 37-44.

2. Лютов С.Н. Создание центра научного книгоиздания в Сибири в контексте системной реорганизации академической науки (1957-1962 гг.) // Книжная культура Сибири и Дальнего Востока в условиях общественных кризисов ХІХ - начала ХХІ в. Новосибирск, 2013. С. 133-140. (Труды ГПНТБ СО РАН. Вып. 3).

3. Лютов С.Н., Панченко А.М. Создание полиграфической базы для академического книгоиздания в Сибири (1957-1971 гг.) // Гуманитарные науки в Сибири. 2014. № 3. С. 52-56.

4. Лизунова И.В. Сибирское академическое книгоиздание: от монополизма к многообразию издательской среды // Научная книга и проблемы книжной культуры на пространстве СНГ: Материалы Междунар. науч. конф. (Москва, 25-26 октября 2012 г.). М., 2012. C. $115-120$

5. Водичев Е.Г. Путь на Восток: формирование и развитие научного потенциала Сибири (середина 50-х - 60-е гг.). Новосибирск, 1993. 204 c.

6. Российская академия наук. Сибирское отделение: исторический очерк. Новосибирск: Наука, 2007. 508 с.

7. Артемов E.T. Формирование и развитие сети научных учреждений АН СССР в Сибири 1944-1980 гг. Новосибирск: Наука, 1990. 189 c.

8. Куперштох H.A. Западно-Сибирский филиал Академии наук CССР: проекты и реалии первой половины XX века // Вестник Том. гос. ун-та. История. 2014. № 2 (28). С. 32-40.
9. Митрейкин Б.Н. Предварительные итоги деятельности Западносибирского филиала АН СССР // Вестник Академии наук СССР. 1945. № 3. С. 107-108.

10. В Президиуме Академии наук СССР. О деятельности Западносибирского филиала // Вестник Академии наук СССР. 1946 № 5-6. С. 117.

11. Иркутский научный центр СО АН СССР. Проблемы развития науки / Академия наук СССР. Сибирское отделение. Иркутск, 1967. C. 3-21.

12. Книговедение: энцикл. словарь. М., 1982. 664 с.

13. Известия Восточных филиалов Академии наук СССР. 1957. № 1. С. 3 .

\section{REFERENCES}

1. Lyutov S.N. The organization of academic publishing in Siberia. Pages of historical documents (1957-1958). Bibliosfera, 2011, no 4, pp. 37-42. (In Russ.)

2. Lyutov S.N. The creating a center of scientific publishing in Siberia in the context of the system organization of academic science (1957-1962). Knizhnya kul'tura Sibiri i Dal'nego Vostoka v usloviyakh obshhestvenny'kh krizisov XIX - nachala XXI v.: Trudy GPNTB SO RAN, 2013, iss. 3, pp. 133-140. (In Russ.)

3. Lyutov S.N., Panchenko A.M. Creation of polygraphic base for the Scientific book publishing in Siberia (1957-1971). Gumanitarnye nauki v Sibiri, 2014, no 3, pp. 52-56. (In Russ.)

4. Lizunova I.V. Sibirskoe akademicheskoe knigiizdanie: ot monopolizma k mnogoobraziyu izdatelskoy sredy. Nauchnaya kniga $i$ problemy knizhnoy kultury na prostranstve $S N G$. Materialy Mezhdunar. nauch. konf. (Moskva, 25-26 oktyabrya 2012 g.). M., 2012, pp. 115-121.

5. Vodichev E.G. The direction to the East: the formation and development of the scientific potential of Siberia (mid-50s - 60s) Novosibirsk, 1993, 204 p. (In Russ.)

6. Russian Academy of Sciences. Siberian Branch: Historical Review. Novosibirsk: Science, 2007, 508 p. (In Russ.)

7. Artyomov E.T. Formation and development of the academic system of scientific institutions in Siberia (1944-1980). Novosibirsk Science, 1990, 189 p. (In Russ.)

8. Kupershtokh N.A. The West-Siberian Branch of the Academy of Sience of the USSR: Projects and realities of the first half of the 20th century. Vestnik Tomskogo gosudarstvennogo universiteta. Istoriya. 2014 no 2 (28), pp. 32-40. (In Russ.)

9. Mitrejkin B.N. Preliminary results of the West-Siberian Branch of the USSR. Vestnik Akademii nauk SSSR. 1945, no 3, pp. 107-108. (In Russ.)

10. The Presidium of the Academy of Sciences of the USSR. The activities of the West Siberian branch. Vestnik Akademii nauk SSSR. 1946, no 5-6, p. 117.

11. The Irkutsk science centre of the Siberian Branch of the USSR Problems of development of science / Academy of Sciences of the USSR. Siberian Branch. Irkutsk, 1967, pp. 3-21. (In Russ.) Russ.)

12. Bibliology: encyclopedic Dictionary. M., 1982, 664 p. (In (In Russ.)

13. Izvestiya Vostochnykh filialov AN SSSR. 1957, no 1, p. 3 